\title{
'WE LOVE READING, BUT...': NIGERIAN CHILDREN ON FACTORS THAT AFFECT THEIR READING HABITS
}

\author{
Isang Awah \\ Faculty of Education, University of Cambridge (United Kingdom)
}

\begin{abstract}
In recent decades, Nigeria has repeatedly had low pass rates in examinations taken at the end of secondary school. There are claims that the low student achievements are largely because Nigerian children do not read for pleasure, even though these claims lack the backing of empirical research. This qualitative study therefore explores reading for pleasure done by a group of 9-12 year olds in a book club in Nigeria. It aims to shed light on the extent to which the children read, how, what, when and why they read, and the factors that affect their engagement with reading for pleasure. A study of children's reading habits is important as some research suggests that reading for pleasure may offer many benefits including reading proficiency, increased general knowledge, and improved vocabulary. Through an interpretivist theoretical perspective, the study gathered data using the methods of collage making, observation, questionnaire, and interviews. Findings indicate that the participants read for pleasure, though their level of engagement with reading for pleasure differs. All the participants read printed books, and a few participants also read digitally. Popular reading materials include fiction, comics, factual books, crime and detective books, and adventure books. The children have different motivations for reading, but many state that reading is fun and interesting. Some research done in the United States and the United Kingdom indicates that factors such as availability of books, choice of texts, pedagogies of reading and an enabling adult affect children's engagement with reading for pleasure. This study examined the relevance of these factors to the participants' reading habits and found that the reading engagement of all the participants may have been, in varying degrees, influenced by them. Other factors that possibly affected the participants' reading habits were the reading environment, reading aloud, and the availability of social networks and affordances that support leisure reading. The findings could provide guidance on practices that strengthen children's engagement in reading for pleasure and thereby help in the improvement of student achievement in Nigeria.
\end{abstract}

Keywords: Reading for pleasure, children readers, factors affecting reading habits, reading engagement, Sub-Saharan Africa.

\section{Introduction and objectives}

Although Nigeria is Africa's most populous country, its student achievement has been repeatedly low, and the improvement of its primary education system has been identified as one of Nigeria's main challenges (Hardman et al, 2008). Educationists have linked the low student achievement to the absence of a reading culture and made repeated calls for the promotion of recreational reading in Nigerian children and youths (Adesulu, 2016). The claim that the low student achievement is because Nigerian children do not read for pleasure is not altogether surprising as recurring evidence suggests that reading for pleasure offers many benefits including reading proficiency (Anderson et al, 1988), increased general knowledge (Stanovich \& Cunningham, 1993), and a raise in the educational standards (Clark \& Rumbold, 2006). Studies also suggest that the reading habits of children are influenced by factors such as pedagogy, the reading environment, access to engaging books, and the presence of an enabling adult (Layne, 2009; Cremin et al, 2014). A review of literature on reading in Nigeria revealed a gap: there is no evidence of a study of the reading habits of children in primary school. Therefore, the study discussed in this paper explored reading for pleasure done by a group of fifteen 9-12-year-olds in a book club, Krown Book Club (KBC), in Nigeria with the aim of shedding light on the children's reading habits and the factors that affected their reading engagement, and possibly, suggesting the strategies that could help them to become more engaged readers. The study was guided by the following research questions: 
1. To what extent do the 9-12-year-olds at $\mathrm{KBC}$ engage in reading for pleasure?

2. How, what, when and why do the 9-12-year-olds in $\mathrm{KBC}$ read for pleasure?

3. What factors affect their reading engagement and what social networks and affordances exist to nurture and support their leisure reading?

In this paper, I shall briefly discuss the extent to which the participants engaged in reading for pleasure; the focus of the paper shall majorly be the factors that affected their reading engagement.

\section{Methodology and methods}

Based on the exploratory nature of the research, I adopted an interpretivist theoretical perspective which enabled me to construe the meaning of the participants' reading engagement from the findings of my study rather than from generally-held perceptions. The methodology used was case study. Data were gathered through the qualitative methods of creating visual images (collage-making), observation, questionnaire and interview. By pasting cut-out papers of different colours on a cardboard, the participants created a collage of their leisure time in the past year. The more time was spent on an activity, the more the activity's assigned coloured paper featured on a collage. I used observation to identify the reading environment KBC provided and what network of resources that support reading it offered. Through questionnaires administered to the participants, their parents and staff members of the book club, I generated data that specifically addressed the research questions, including questions about the participants' out-of-school activities, reading behaviours, attitudes to reading, estimates of their reading frequencies, books read, and home resources that supported reading. The interviews explored the reading habits of the participants, their perspectives on reading and their motivations for reading.

\section{Discussions}

Findings indicate that all the participants read for pleasure, though their level of engagement differed. Findings also reveal that the reading engagement of all the participants may have been, in varying degrees, influenced by factors such as the pedagogy of reading, choice of text, availability of text, the reading environment, and the availability of social networks and affordances that support leisure reading.

\subsection{The Extent to which the children read}

Findings from the participants' collages, some of which are figures 1, 2, 3 and 4 below, reveal that the extent to which the participants read for pleasure varied. In the collages, reading is represented by the colour, yellow:

Figure 1

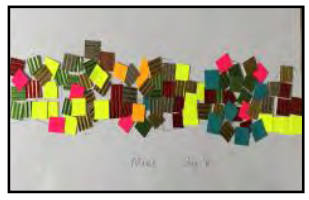

Figure 2

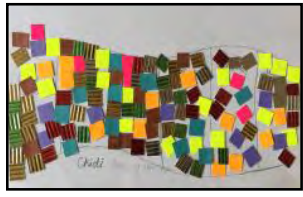

Figure 3

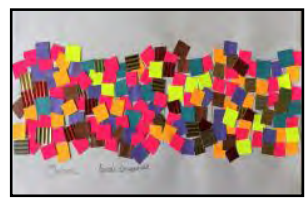

Figure 4

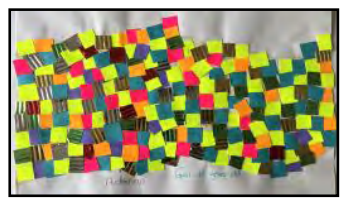

Like data from the collages, the interview and questionnaire data indicate that the participants had a range of reading engagement and attitudes; some of the children were engaged readers who read a lot, the majority of participants read moderately, and a few read minimally. Most of the children read for about 30 minutes each time they read, a few read for a longer period, and some read for a much shorter time than 30 minutes. Some of the participants only read printed materials, but most of them read printed as well as electronic materials, and a few listened to audio books in addition to reading both printed and electronic materials. Popular reading materials included fiction, comics, factual books, crime and detective books, and adventure books. Favourite authors included Jeff Kinney, Shakespeare, Ben Carson, R. L. Stine, Geronimo Stilton, Enid Blyton and Roald Dahl. The children had different motivations for reading, but many stated that reading was fun and interesting.

\subsection{Factors that affected the children's reading habits}

Layne (2009) argues that even though reading is a choice, children can be impacted by certain factors in such a way that they will more likely than not make the choice to read. In this section, I will analyse the different factors that affected the reading habits of my study's participants. 
3.2.1. Pedagogy of reading. Studies indicate that children's attitude to reading and literary texts is often affected by the reading practices used (Layne, 2015; Rosenblatt, 1978/1994; Meek, 1988). A recurrent theme in the data of both group and individual interviews in my study was reading being accompanied by questions. Most of the children attended schools where the teachers did not read aloud to the class, but almost all the participants whose teachers read to the class reported that the teachers usually asked questions after the reading aloud session. The children stated that they did not like being asked questions after reading of any kind. Peter's comments below are representative of the views expressed by most participants on having to answer questions after a reading aloud session:

Peter: It kind of makes me feel like they're going to give us an exam or a test afterwards. So, I'll have to really listen to it...If it's a story, they should read aloud and have no questions...

Pennac (2006) advocates that children should be allowed to read purely for the pleasure that reading gives rather than as a means of teaching literary skills as doing otherwise would make the child cease associating reading with pleasure, which may have the likely consequence of making the child stop reading. Based on my study's findings, I argue that it is possible that many children who do not read much may have been negatively impacted by the pedagogy of reading both at home and in the school.

3.2.2. Choice of texts. Research indicates that the opportunity to choose the texts they read greatly affects children's motivation to read (Clark \& Phythian-Sence, 2008; Cremin, 2015). All the children said that they always self-selected the books they read at KBC and were free to change the books at any time. Most participants also self-selected the books they read for pleasure at home. However, this was not the case for Mike whose father usually chose the books he read at home, most of which Mike did not like.

IA: If you don't like reading it, must you still read it?

Mike: Yes, I must...

Mike described the books his father gave him to read as 'hard books'. He liked Enid Blyton books, but his father did not allow him read these. It is possible that by stopping Mike from reading the books which Mike liked and forcing him to read the books he did not like, Mike's father was reducing Mike's potential to engage in leisure reading. Adanna also complained that her father stopped her from reading Diary of a Wimpy Kid books because "they don't teach anything." A few other participants also complained that their teachers chose the books they read during the reading time at school, and that usually, they did not like the books and so did not read them. There are arguments that people should be encouraged to read what they enjoy reading in whatever format they prefer as doing otherwise may reduce the potential for pleasurable engagement in reading (Cremin, 2015). Findings from this study support these arguments.

3.2.3. Reading aloud. Reading aloud has been identified as a key factor in helping children foster a love for reading (Layne, 2009, 2015; Lockwood, 2008). A few participants said their parents had read to them when they were younger and that this had stirred in them an interest in leisure reading. However, most participants said that they never had the experience of being read to when they were young. For many participants, outside KBC, no-one read aloud to them. Six participants reported that someone at school, usually the class teacher, sometimes read aloud to their class while two participants reported that someone at home read aloud to them. Many participants claimed that they enjoyed being read to at KBC, and that the reading aloud made them interested in reading the book. It is likely that many Nigerian children would read more if they had someone regularly read aloud to them in their homes as well as in their schools.

3.2.4. Access to engaging books. Studies indicate that another factor that plays a critical role in children's engagement with reading for pleasure is the access to suitable and engaging texts (Anderson et al., 1985; Lockwood, 2008). Data from my study indicate that access to engaging texts also affected the extent to which the participants read. Nine participants gave a negative answer to the question that sought to know if they usually had access to the texts they would like to read, and the other children answered in the affirmative. Apart from one child, all the children who responded to the question of access to books with a 'yes' response gave further responses that showed that it was not always easy for them to access the texts they wanted to read. Findings suggest that outside KBC, some participants had no access to books they liked. The larger implication of this is that children whose parents could not afford to register them at $\mathrm{KBC}$ or a book club may not have access to engaging materials. It is therefore possible that more children would spend more time on leisure reading if they always had access to the reading materials that they liked. 
3.2.5. An enabling adult. Studies on successful literacy achievement often appear to feature either a teacher or a parent (Westbrook, 2013; Cremin et al., 2014). Chambers (1991) places an enabling adult at the centre of the reading circle, a circle he draws to show the sequence of activities in reading. An enabling adult here refers to an adult who loves books and recreational reading, has knowledge of children's literature, discusses books regularly with the child in a manner the child finds engaging and appealing, knows the child's reading tastes, suggests suitable and engaging books to the child, and reads aloud to the child. Most of the children in my study said that their parents read a lot, and some discussed books with them. A few participants had enabling adults that were non-parents. For instance, Paul's 19 year old brother was an engaged reader who showed much interest in Paul's leisure reading and often discussed books with Paul. A few participants stated that their teachers sometimes discussed the books they had read with the class. Unfortunately, for some participants, it was only at KBC that they had an enabling adult as neither their parents nor teacher showed much interest in their reading. Data from my study indicate that one reason the children read the way they did is because they had one or more enabling adults in their lives, implying that some children may be better engaged readers if they had an enabling adult in their lives.

3.2.6. The reading environment. According to Chambers (1991), the reading environment is made up of the place (setting), the availability of books, time available for reading, interruptions the reader may experience, the mood of the reader, and the attitude of the reader; however, I would like to also include the weather as it is a part of the features of a place and also featured prominently in my data. When I asked the children to say what things stopped them from reading or completing a book at any time, the subject of the hot weather came up as one of the factors that prevented them from either reading or completing a book. There were also complaints about not having a comfortable place to read, and about having to read in a noisy place. Shehu reported that he could not read in his home in the daytime and only read at night because his house was "really noisy". Chambers (1991) argues that where readers read affects how they read and their pleasure, willingness and concentration. My data support this argument and lead me to suggest that perhaps more children would read more if they had the right reading environment.

3.2.7. Social networks and affordances that support leisure reading. According to Lockwood (2008), schools that successfully promote reading provide easy access to plenty of suitable texts. All the children in my study attended a school that had a library. However, the size of the school library and the number of books in the library varied and were largely dependent on how expensive the tuition fee in the school was. The more expensive the school fee was, the more equipped the library was, and vice versa. In addition, different schools had different rules and policies that governed the students' use of the library. In some schools, students were not allowed into the library, or where they were allowed, could not borrow books. For instance, in Rose's school, the children were not allowed into the library; the headmistress randomly selected books and gave the children to read, and the children had no say in this. Findings also show that in some of the school libraries, there were no spaces designed for reading. Therefore, though school libraries have the potential to encourage children to read and build a reading culture, in the schools my study participants attended, this potential was yet to be fully activated and realized. It is possible that many children would be motivated to read more if the library in their school adopted strategies that could help the children to become better engaged readers.

Public libraries play a crucial role in nurturing children's love for reading and their development of a reading culture, and also help to close the book gap between children of different backgrounds by providing all children with access to high-quality reading materials (Celano \& Neuman, 2001). In addition to exposing children to great quantities of a wide variety of high-quality books of various topics, genres, and perspectives, many libraries offer literary activities such as author readings and summer reading groups which nurture children's interests in reading and in books (Krolak, 2005). Unfortunately, 14 of the 15 children in my study had never been to a public library and did not know of any. The implication is that these children do not have the opportunity of benefitting from the many literary exposures and experiences that a public library could offer and have little or limited social networks and affordances that nurture and support their leisure reading. Although evidence points to the fact that the children in my study read, it is possible that they would be more engaged readers if there were public libraries that provided them with many books of different genres and organized literary programmes such as the summer reading challenge which provide exciting opportunities for children to read more. 


\section{Conclusion}

In this paper, I have provided insights into some of the factors that affected the participants' reading engagement. I hope that these insights will lead parents and educators to reappraise their support of children's reading habits and adopt practices that will encourage children's appreciation of reading. This, I believe, will help more children in Nigeria to engage more in reading for pleasure and, ultimately, lead to a strengthening of Nigeria's education system and an improvement in student attainment.

\section{References}

Adesulu, D. (2016, March 24). 80\% fail NECO, WAEC, JAMB over dearth of reading culture - Ignite Africa. Vanguard. Retrieved July 7, 2016, from http://www.vanguardngr.com/2016/03/80-failneco-waec-jamb-dearth-reading-culture-ignite-africa/

Anderson, R. C., Hiebert, E. H., Scott, J. A., \& Wilkinson, I. A G. (1985). Becoming a Nation of Readers: The Report of the Commission on Reading. Washington, DC: US. Department of Education.

Anderson, R., Wilson, P., \& Fielding, L. (1988). Growth in reading and how children spend their time outside of school. Reading Research Quarterly, 23(3), 285-303. Retrieved October 27, 2015, from http://www.jstor.org/stable/748043

Celano, D., \& Neuman, S. (2001). The Role of Public Libraries in Children's Literacy Development: An Evaluation Report. Pennsylvania Library Association Technical Report, Pennsylvania Department of Education.

Chambers, A. (1991). The Reading Environment: How Adults Help Children Enjoy Books. Stroud: Thimble Press.

Clark, C., \& Phythian-Sence, C. (2008). Interesting Choice: The (Relative) Importance of Choice and Interest in Reader Engagement. London: National Literacy Trust.

Clark, C., \& Rumbold, K. (2006). Reading for Pleasure: A Research Overview. London: National Literacy Trust.

Cremin, T. (2015, September 25). Requiring Reading for Pleasure. Cambridge Primary Review Trust. Retrieved June 27, 2017, from http://cprtrust.org.uk/cprt-blog/requiring-reading-for-pleasure/

Cremin, T., Mottram, M., Collins, F. M., Powell, S., \& Safford, K. (2014). Building Communities of Engaged Readers: Reading for Pleasure. London: Routledge.

Hardman, F., Abd-Kadir, J., \& Smith, F., (2008). Pedagogical renewal: improving the quality of classroom interaction in Nigerian primary schools. International Journal of Educational Development, 28(1), 55-69. Retrieved September 16, 2017, from https://doi.org/10.1016/j.ijedudev.2007.02.008

Krolak, L. (2005). The role of libraries in the creation of literate environments. Paper commissioned for the EFA Global Monitoring Report 2006, Literacy for Life. Hamburg, Germany: UNESCO Institute for Education (UIE).

Layne, S. (2009). Igniting a Passion for Reading: Successful Strategies for Building Lifetime Readers. Portland, Maine: Stenhouse Publishers.

Layne, S. (2015). In Defense of Read-Aloud: Sustaining Best Practice. Portland, Maine: Stenhouse Publishers.

Lockwood, M. (2008). Promoting Reading for Pleasure in the Primary Classroom. London: Sage.

Meek, M. (1988). How Texts Teach What Readers Learn. Stroud: Thimble Press.

Pennac, D. (2006). The Rights of the Reader. London: Walker Books.

Rosenblatt, L. M. (1978/1994). The Reader, The Text, The Poem: The Transactional Theory of the Literary Work. Carbondale \& Edwardsville: Southern Illinois University Press.

Stanovich, K. E., \& Cunningham, A. E. (1993). Where does knowledge come from? Specific associations between print exposure and information acquisition. Journal of Educational Psychology, 85(2), 211-229. Retrieved August 24, 2016, from doi: 10.1037/0022-0663.85.2.211

Westbrook, J. (2013). Reading as a hermenuetical endeavour: Whole-class approaches to teaching narrative with low-attaining adolescent readers. Literacy, 47(1), 42-49. Retrieved June 3, 2016, from doi:10.1111/j.1741-4369.2012.00680.x 